\title{
DESINFETANTES DE ALTO NÍVEL ALTERNATIVOS AO GLUTARALDEÍDO PARA PROCESSAMENTO DE ENDOSCÓPIOS FLEXÍVEIS
}

Eliane Molina Psaltikidis ${ }^{1}$, Mirtes Loeschner Leichsenring ${ }^{2}$, Marlene Hitomi Yoshida Nakamura ${ }^{3}$, Joaquim Murray Bustorff-Silva ${ }^{4}$, Luis Augusto Passeri ${ }^{5}$, Sonia Isoyama Venâncio ${ }^{6}$

1Enfermeira. Mestre em Enfermagem. Universidade Estadual de Campinas. Campinas-SP-Brasil.

${ }^{2}$ Enfermeira. Especialista em Enfermagem Médico-cirúrgica. Universidade Estadual de Campinas. Campinas-SP-Brasil.

${ }^{3}$ Enfermeira. Especialista em Pediatria e Puericultura. Universidade Estadual de Campinas. Campinas-SP-Brasil.

${ }^{4}$ Médico. Universidade Estadual de Campinas. Campinas-SP-Brasil.

${ }^{5}$ Cirurgião Dentista. Universidade Estadual de Campinas. Campinas-SP-Brasil.

${ }^{6}$ Médica. Doutora em Saúde Pública. Secretaria Estadual de saúde. São Paulo-SP-Brasil.

RESUMO: Endoscópios flexíveis são fundamentais em diversas especialidades médicas; em geral são termossensíveis, semicríticos e submetidos à desinfecção de alto nível. O glutaraldeído é largamente utilizado para este fim, devido à alta compatibilidade e baixo custo, porém, a tolerância de micobactérias e a toxicidade ocupacional pressionam por adoção de germicidas alternativos. Foi realizada revisão sistemática com objetivo de buscar evidências sobre a efetividade, toxicidade e potenciais danos causados aos endoscópios pelos germicidas, alternativos ao glutaraldeído, disponíveis no mercado brasileiro. Foram identificadas, em 13 bases eletrônicas, 822 publicações, entre 2008 e 2013. Destas, foram selecionados 23 estudos, considerando a melhor qualidade de evidência disponível. As publicações apontaram para a superioridade do ácido peracético e do ortoftalaldeído quanto à eficácia na desinfecção de alto nível. Somente o ortoftalaldeído apresentou evento adverso claramente relacionado à sua utilização. Não há evidências suficientes para afirmar que algum destes germicidas possui maior potencial de danos aos equipamentos.

DESCRITORES: Desinfecção; Endoscópios; Glutaraldeído; Toxicidade.

\section{HIGH-LEVEL DISINFECTANTS ALTERNATIVE TO GLUTARALDEHYDE FOR PROCESSING FLEXIBLE ENDOSCOPES}

\begin{abstract}
Flexible endoscopes are fundamental in various medical specialities; in general they are heat-sensitive, semicritical, and subject to high level disinfection. Glutaraldehyde is largely used for this purpose, due to its high compatibility and low-cost. However, its tolerance of mycobacteria and occupational toxicity lead to pressure being applied for the adoption of alternative germicides. A systematic review was undertaken aiming to seek evidence regarding the effectiveness, toxicity and potential harm caused to the endoscopes by those germicides which are alternative to glutaraldehyde and which are available on the market in Brazil. A total of 822 publications was identified in 13 electronic databases, between 2008 and 2013. Of these, 23 studies were selected, considering the best quality of evidence available. The publications point to the superiority of peracetic acid and of orthophthaldehyde regarding efficacy in high level disinfection. Only orthophthaldehyde presented an adverse event clearly related to its use. There is insufficient evidence to assert that any of these germicides has greater potential for harm to the equipment. DESCRIPTORS: Disinfection; Endoscopes; Glutaraldehyde; Toxicity.
\end{abstract}

\section{DESINFECTANTES DE ALTO NIVEL ALTERNATIVOS AL GLUTARALDEHÍDO PARA PROCESAMIENTO DE ENDOSCOPIOS FLEXIBLES}

RESUMEN: Fundamentales en diversas especialidades médicas, los endoscopios flexibles son, normalmente, termosensibles, semicríticos y sometidos a la desinfección de alto nivel. El glutaraldehído es muy utilizado para esa finalidad, en razón de la gran compatibilidad y bajo custo, pero la tolerancia de microbacterias y el hecho de ser o no tóxico de modo ocupacional presionan por la adopción de germicidas alternativos. Fue realizada revisión sistemática con el objetivo de buscar evidencias sobre la efectividad, toxicidad y potenciales daños causados a los endoscopios por los germicidas alternativos al glutaraldehído, disponibles en el mercado brasileño. Fueron identificadas, en 13 bases electrónicas, 822 publicaciones, entre 2008 y 2013. De estas, fueron seleccionados 23 estudios, considerando la mejor cualidad de evidencia disponible. Las publicaciones apuntaron para la superioridad del ácido peracético y del ortoftalaldehído cuanto a la eficacia en la desinfección de alto nivel. Solamente el ortoftalaldehído presentó evento adverso claramente relacionado a su utilización. No hay evidencias suficientes para afirmar que algun deestes germicidas presenta mayor potencial de daños a los equipos. DESCRIPTORES: Desinfección; Endoscopios; Glutaraldehído; Toxicidad. 


\section{INTRODUÇÃO}

Os benefícios da utilização de endoscópios flexíveis para a prevenção, diagnóstico e tratamento de muitas doenças são inquestionáveis e seu uso é bem estabelecido em diversas especialidades médicas ${ }^{(1)}$. Esses equipamentos são termossensíveis, complexos, com lumens longos e estreitos, válvulas e comandos intrincados que necessitam de rigoroso processo de limpeza e desinfecção, a cada uso, para evitar a transmissão de infecções diversas ${ }^{(1-2)}$. Endoscópios podem ser classificados como críticos ou semicríticos, conforme a definição de Spauding que considera o nível de colonização dos órgãos onde se realiza o procedimento ${ }^{(2)}$. Os endoscópios utilizados em trato digestório, alto e baixo, e os broncoscópios adentram o corpo humano por orifício natural, ricamente colonizado, sendo considerados equipamentos semicríticos. Os cistoscópios, embora considerados como semicríticos, devem ser submetidos, preferencialmente, à esterilização, devido a sua utilização em diversos procedimentos cirúrgicos. Os endoscópios, artroscópios e óticas rígidas utilizados em cirurgias, são classificados como críticos e devem ser esterilizados, obrigatoriamente ${ }^{(2)}$.

Os endoscópios semicríticos (gastroduodenoscópios, colonoscópios, broncoscópios, nasofobriscópios e cistoscópios), por serem utilizados com grande frequência e em procedimentos ambulatoriais de curta duração, constituem um desafio para o adequado processo de desinfecção, sendo o alvo do presente estudo. A incidência de infecção associada às endoscopias, supostamente, é baixa, cerca de 1 em 1,8 milhões de procedimentos. Contudo, surtos de infecção relacionados aos procedimentos endoscópicos são destacados na literatura, demonstrando que as principais causas são falhas no processo de limpeza e desinfecção ${ }^{(1-3)}$. Este processamento, no Brasil, deve seguir as boas práticas para Centros de Material e Esterilização e para Serviços de Endoscopia, determinadas pelas Resoluções da Diretoria Colegiada da Agência Nacional de Vigilância Sanitária n. 15/2012 e n. 6/2013 ${ }^{(4-5)}$.

Após o uso, os endoscópios semicríticos devem ser submetidos à limpeza minuciosa e à Desinfecção de Alto Nível (DAN) que elimina todos os microrganismos em forma vegetativa (vírus, fungos, bactérias e micobactérias) tendo, inclusive, ação parcial sobre os esporos ${ }^{(2)}$. A DAN pode ser realizada por método manual ou automatizado e atender aos requisitos estabelecidos pela regulamentação brasileira específica( ${ }^{(6)}$, que dispõe sobre produtos químicos com ação antimicrobiana utilizados em materiais críticos e semicríticos. O nível de ação dos desinfetantes, exigido nesta resolução, é comprovado frente ao Staphylococcus aureus, Salmonella choleraesuis, Escherichia coli, Pseudomona aeruginosa, Trichophyton mentagrophytes, Candida albicans, Mycobacterium smegmatis, Mycobacterium bovis(BCG), Mycobacterium massiliense INCQS 00594, Bacillus subtilise Clostridium sporogenes ${ }^{(6)}$.

Apesar de indispensáveis para a desinfecção, os germicidas têm sido, frequentemente, associados a danos aos endoscópios tais como corrosão, prejuízo na fixação das lentes, amolecimento do revestimento externo e incrustação de sujidade nos lumens ${ }^{(1-2)}$. Pelo fato de serem equipamentos delicados e de alto custo há o receio de se adotar novos germicidas, especialmente quando não há autorização expressa dos fabricantes, podendo levar ao cancelamento da garantia de endoscópios novos. A maioria destes recomenda apenas o uso de glutaraldeído; outros autorizam o uso de ácido peracético, porém, de formulação e marca específicas. São germicidas para DAN aprovados para uso no Brasil:

Glutaraldeído (GLU) é um dialdeído saturado, ligeiramente ácido, volátil e com odor pungente; age pela alquilação de grupos sulfidrila, hidroxila, carboxila e amino dos microrganismos, alterando seu DNA, RNA e síntese proteica. A ação esporicida ocorre pelo endurecimento das camadas externas; ainda é o desinfetante mais utilizado no mundo, por método manual ou automatizado, em concentração de $2 \%$ a 3,4\%. Devido aos eventos adversos, observados em pacientes e profissionais, foram publicadas normas $^{(4,7-8)}$ com várias exigências: manipulação do GLU em área privativa e bem ventilada, uso de equipamentos de proteção individual e coletiva, monitoramento ambiental e avaliação médica periódica dos profissionais. Há relatos de casos de microrganismos intrinsecamente tolerantes, especificamente micobactérias de crescimento rápido ${ }^{(1-2)}$. Entre 2006 a 2008, no Brasil, ocorreu um surto de infecções pós-operatórias causadas por micobactéria de crescimento rápido, com mais de 2 mil $\operatorname{casos}$ notificados ${ }^{(9)}$, o surto foi 
fortemente associado a procedimentos de videocirurgia, em que o instrumental recebeu DAN com GLU. A inefetividade do GLU frente às micobactérias foi confirmada por estudos das cepas causadoras das infecções ${ }^{(10-11)}$. A fim de conter o surto foram aplicadas medidas pela Agência Nacional de Vigilância Sanitária brasileira proibindo a esterilização química líquida e aumentando as exigências para registro de desinfetantes e esterilizantes ${ }^{(6,12-13)}$.

Ortoftalaldeído (OPA) é um aldeído bem solúvel e estável, coloração azul, pH 7,5, sensível à luz ultravioleta e a oxidação pelo ar; seu mecanismo de ação é semelhante ao do GLU, porém com baixa ação esporicida que ocorre pelo bloqueio da germinação. Este aldeído pode ser utilizado de forma manual ou automatizada, em concentração de 0,55\%; apesar de ser menos volátil que o GLU, também necessita ser manipulado em área devidamente ventilada e com uso de equipamentos de proteção individual ${ }^{(1-2)}$.

Ácido Peracético (AP) está comercialmente disponível em formulações aquosas ou em pó, para uso manual ou automatizado, com rápida ação sobre microrganismos vegetativos. A concentração de seu uso e o pH da solução são fórmula-dependentes; este desinfetante age pela desnaturação proteica, aumento da permeabilidade da membrana celular pela ruptura dos radicais sulfidrila(-Sh) e ligações de enxofre (SS), oxidando as enzimas microbianas essenciais ${ }^{(1-2)}$. No Brasil, o uso de AP como desinfetante de endoscópios é relativamente recente.

Água Ácida Eletrolítica (AAE) é gerada por equipamento que faz a eletrólise do cloreto de sódio ${ }^{(1,2)}$; opera com $\mathrm{pH} \geq 2,7$, com um potencial de óxido-redução $1000 \mathrm{mV}$ e formação de cloro livre na concentração de $10 \pm 2$ ppm. Este produto age pela ação sinérgica do $\mathrm{pH}$, potencial de óxido-redução e oxidação do ácido hipocloroso que inibe o metabolismo dos microrganismos ${ }^{(1-2)}$. No Brasil, o equipamento disponível é de origem japonesa, denominado Clean Top ${ }^{\circledR(14)}$.

Apresenta-se de forma resumida no Quadro 1 vantagens e desvantagens dos desinfetantes de alto nível.

Frente ao exposto, o objetivo do estudo consiste em revisão sistemática da literatura para análise dos desinfetantes de alto nível, alternativos ao GLU, quanto à efetividade, à toxicidade aos pacientes e profissionais de saúde e potenciais danos aos endoscópios.

\section{MÉTODO}

Adotou-se a metodologia "PICO" para elaboração da pergunta da pesquisa: o problema de saúde ao qual se aplica ( $\mathrm{P}=$ endoscópios flexíveis semicríticos- digestivos, respiratórios e cistoscópios), a tecnologia ou intervenção a ser avaliada ( $\mathrm{I}=\mathrm{AP}$, OPA e AAE para uso manual ou automatizado), as tecnologias alternativas de comparação $(\mathrm{C}=\mathrm{GLU})$ e os resultados ou desfechos em saúde de interesse $(\mathrm{O}=$ efetividade na DAN, toxicidade e danos ao equipamento ${ }^{(15)}$. A pergunta foi definida como "Qual a efetividade, a toxicidade e os potenciais danos aos endoscópios dos desinfetantes de alto nível alternativos ao glutaraldeído?"

Os critérios de inclusão dos estudos foram: 1. melhor evidência possível na literatura, frente aos desfechos estabelecidos, considerando o nível de evidência científica dos estudos segundo a Oxford Centre for Evidence Based Medicine(15); 2. publicações a partir de 2008, pois se adotou, como ponto de partida, dois importantes guidelines publicados naquele ano sobre processamento de endoscópios ${ }^{(1-2)}$. Os termos utilizados para as buscas estão apresentados no Quadro 2, pelas quais foram identificadas 822 publicações até junho de 2013. A avaliação de cada estudo foi discutida pelos autores e por um revisor independente. 
Quadro 1 - Vantagens, desvantagens e toxicidade dos desinfetantes de alto nível. Campinas-SP-Brasil, 2013

\begin{tabular}{|c|c|c|c|}
\hline Produto & Vantagens & Desvantagem & Toxicidade \\
\hline GLU & $\begin{array}{l}\text { - Baixo custo } \\
\text {-Excelente } \\
\text { compatibilidade com } \\
\text { todos os materiais } \\
\text { - Boa estabilidade (14 a } \\
28 \text { dias) }\end{array}$ & $\begin{array}{l}\text { - Baixa atividade } \\
\text { esporicida e } \\
\text { micobactericida a } 25^{\circ} \mathrm{C} \\
\text { - Fixa material orgânico, } \\
\text { favorecendo a formação } \\
\text { de biofilme } \\
\text { - Requer avaliação } \\
\text { periódica da função } \\
\text { pulmonar dos } \\
\text { profissionais que } \\
\text { manipulam a solução } \\
\text { - Requer tempo mínimo } \\
\text { de } 20 \text { minutos para } \\
\text { desinfecção } \\
\text { - Volátil }\end{array}$ & $\begin{array}{l}\text { - Irritante para nariz, } \\
\text { garganta, olhos e pele } \\
\text { - Promove } \\
\text { sensibilização } \\
\text { - Pode causar colite em } \\
\text { pacientes }\end{array}$ \\
\hline OPA & $\begin{array}{l}\text { - Excelente } \\
\text { compatibilidade } \\
\text { - Boa estabilidade ( } 7 \text { a } \\
14 \text { dias) } \\
\text { - Tempo de desinfecção } \\
\text { a partir de } 12 \text { minutos }\end{array}$ & $\begin{array}{l}\text { - Baixa e lenta ação } \\
\text { sobre esporos } \\
\text { - Volátil, mas muito } \\
\text { inferior ao GLU } \\
\text { - Fixa material orgânico, } \\
\text { mas muito inferior ao GLU } \\
\text {-Recomenda-se } \\
\text { neutralização do produto } \\
\text { antes do descarte }\end{array}$ & $\begin{array}{l}\text { - Irritante para olhos e } \\
\text { trato respiratório } \\
\text { - Poucos dados sobre } \\
\text { eventos por longo } \\
\text { tempo de exposição } \\
\text { - Anafilaxia com } \\
\text { cistoscopias repetidas } \\
\text { em pacientes } \\
\text { oncológicos } \\
\end{array}$ \\
\hline $\mathrm{AP}$ & $\begin{array}{l}\text { - Tempo de desinfecção } \\
\text { a partir de } 10 \text { minutos } \\
\text { - Estabilidade fórmula } \\
\text { dependente podendo } \\
\text { ser de } 1 \text { a } 30 \text { dias } \\
\text { - Atóxica ao meio } \\
\text { ambiente } \\
\text { - Não fixa material } \\
\text { orgânico }\end{array}$ & $\begin{array}{l}\text { - Custo elevado } \\
\text { - Odor de vinagre } \\
\text { - Compatibilidade } \\
\text { variável, podendo ser } \\
\text { corrosivo para algumas } \\
\text { ligas e metais. } \\
\text { - Pode coagular } \\
\text { proteínas, dependendo } \\
\text { do pH }\end{array}$ & $\begin{array}{l}\text { - Dependendo } \\
\text { da formulação, } \\
\text { especialmente do } \mathrm{pH}, \\
\text { pode ser irritante para } \\
\text { olhos e trato respiratório }\end{array}$ \\
\hline $\mathrm{AAE}$ & $\begin{array}{l}\text { - Tempo de desinfecção } \\
\text { a partir de } 7 \text { minutos } \\
\text { - Não é tóxico para o } \\
\text { profissional } \\
\text { - Baixo custo do } \\
\text { processo } \\
\text { - Amplo espectro de } \\
\text { ação }\end{array}$ & $\begin{array}{l}\text { - Pode ser inativado em } \\
\text { presença de material } \\
\text { orgânico } \\
\text { - Pode coagular proteínas, } \\
\text { dependendo do pH } \\
\text { - O equipamento } \\
\text { processa apenas } \\
\text { endoscópios digestivos }\end{array}$ & - Não há relatos \\
\hline
\end{tabular}

Legenda: GLU- Glutaraldeído; OPA- Ortoftalaldeído; AP- Ácido Peracético; AAE- Água Ácida Eletrolítica 
Quadro 2 - Estratégia de busca e palavras chaves. Campinas-SP-Brasil, 2013

\begin{tabular}{|l|l|}
\hline Fonte & Palavras chave \\
\hline PUBMED & $\begin{array}{l}\text { (disinfection[Title/Abstract]) AND (endoscopy[Title/Abstract]) AND } \\
\text { ("2008"[Date - Publication] : "2012"[Date - Publication]) }\end{array}$ \\
\hline EMBASE & $\begin{array}{l}\text { 'glutaraldehyde'/exp AND 'endoscopy'/exp AND 'disinfection'/exp; } \\
\text { 'peracetic acid'/exp AND 'endoscopy'/exp AND 'disinfection'/exp; } \\
\text { 'phthalaldehyde'/exp AND 'endoscopy'/exp AND 'disinfection'/exp; } \\
\text { superoxidized water; 'endoscopy'/exp AND 'disinfection'/exp AND (2008:py } \\
\text { OR 2009:py OR 2010:py OR 2011:py OR 2012:py) }\end{array}$ \\
\hline COCHRANE LIBRARY & Disinfection and endoscopy \\
\hline BANDOLIER & Disinfection \\
\hline CRD & (disinfection) AND (endoscopy) FROM 2008 TO 2012 \\
\hline SUMSEARCH & disinfection AND endoscopy \\
\hline LILACS & Disinfection and endoscopy \\
\hline HTAI & Disinfection and endoscopy \\
\hline $\begin{array}{l}\text { PORTAL EVIDÊNCIA } \\
\text { BIREME }\end{array}$ & Disinfection \\
\hline BDENF & Disinfection and endoscopy \\
\hline GOOGLE AVANÇADO & $\begin{array}{l}\text { Tudo no título: glutaraldehyde endoscopy acima 2008; tudo no título: Ortho- } \\
\text { phthalaldehyde disinfection acima 2008; tudo no título: peraceticacid } \\
\text { disinfection acima 2008; tudo no título: superoxidized water disinfection acima } \\
\text { 2008; tudo no título: Electrolyzed Acid Water disinfection acima 2008. }\end{array}$ \\
\hline $\begin{array}{l}\text { BANCO DE TESES } \\
\text { BDTD }\end{array}$ & $\begin{array}{l}\text { titulo:"desinfecção" \#ano_defesa:: 2008; titulo:"endoscopia" \#ano_ } \\
\text { defesa::>2008; titulo:"glutaraldeído" \#ano_defesa::>2008; titulo:"ácido } \\
\text { peracético" \#ano_defesa::>2008; titulo:"água ácida" \#ano_defesa::>2008 }\end{array}$ \\
\hline
\end{tabular}

\section{RESULTADOS}

A Figura 1 apresenta as diferentes etapas adotadas para seleção dos estudos. Os motivos de exclusão da grande parte das publicações foram: texto de opinião de especialistas, não abordar os desfechos de interesse e presença de importante viés metodológico. Ao término da seleção foram incluídas 23 publicações: 1 revisão sistemática; 2 guidelines; 1 avaliação de tecnologia em saúde; 9 estudos experimentais; 3 estudos descritivos e, por fim, 7 relatos de casos referentes a toxicidade dos germicidas. As publicações são provenientes de 12 países, sendo os mais frequentes Brasil e Estados Unidos da América, cada um com seis estudos.

O período de 2008 a 2010 concentrou 74\% das publicações. Quanto aos desfechos de interesse, 14 estudos abordaram efetividade da DAN, nove também analisaram a toxicidade dos germicidas e apenas quatro citaram aspectos referentes a danos aos equipamentos.

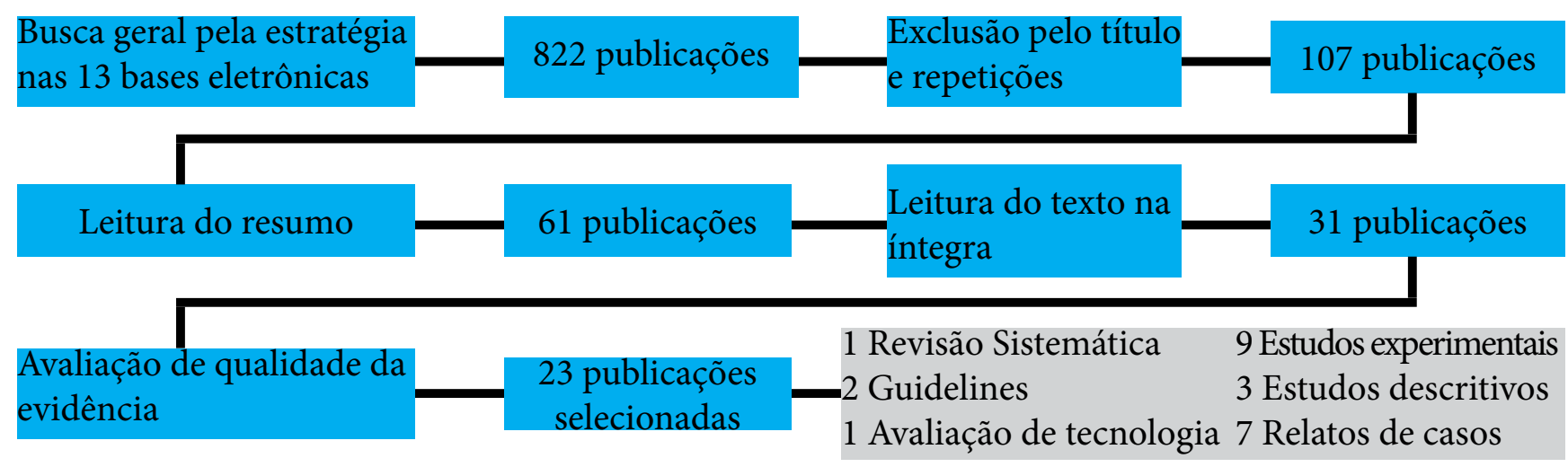

Figura 1- Resumo das etapas de seleção dos estudos. Campinas-SP-Brasil, 2013 


\section{DISCUSSÃO}

Quanto à efetividade da DAN há consenso na literatura sobre os endoscópios digestivos serem semicríticos, no entanto, permanecem questionamentos sobre a necessidade de esterilização dos broncoscópios e cistoscópios ${ }^{(16)}$.

Três estudos analisaram a ação dos desinfetantes frente a biofilmes. Um destes indica que o AP tem menor capacidade de fixação de proteína residual e biofilme, em relação ao GLU e AAE ${ }^{(17)}$. Outra publicação ${ }^{(18)}$ analisou a remoção de biofilme, exopolissacarídeos e bactérias em corpos amostrais que simulavam os canais de endoscópios flexíveis, após uso dos diferentes desinfetantes. O mais eficiente foi o GLU automatizado (95,24\%), apesar da sua sabida ação na fixação de material orgânico. O fato foi justificado devido à dupla limpeza realizada pelo equipamento. O AP por método manual apresentou o pior resultado (23,81\%). Se considerada a ausência de todos os resíduos, o AP por método automatizado obteve o melhor resultado $(66,67 \%)$ e a $\mathrm{AAE}$ o pior $(0 \%)^{(18)}$. $\mathrm{O}$ terceiro estudo avaliou apenas o AP, com resultados satisfatórios frente aos microrganismos testados, inclusive em biofilme ${ }^{(19)}$.

Uma revisão sistemática ${ }^{(20)}$ alertou sobre a ineficácia de todos os desinfetantes de alto nível, utilizados no Brasil para microrganismos da subclasse Coccidia, sendo o principal representante o gênero Cryptosporidium, que pode causar infecção entérica em pacientes imunocomprometidos. Apesar disto impactar no processamento dos colonoscópios, os autores afirmam que ainda não há recomendação de mudança das práticas atuais por falta de evidências do seu impacto na ocorrência de infecção relacionada à colonoscopia.

Outro microrganismo desafiador é o Micobacterium massiliense INCQS 549, uma micobactéria de crescimento rápido, que se mostrou tolerante ao GLU em altas concentrações e longo tempo de exposição ${ }^{(21-22)}$. Frente ao AP e OPA, esta micobactéria apresentou susceptibilidade na concentração e tempo de exposição utilizados na prática assistencial ${ }^{(23)}$. Estes achados levaram ao estabelecimento de nova legislação para aprovação, registro e uso de desinfetantes ${ }^{(4,6,9,12-13,24)}$.
O uso de desinfetadora de endoscópios por AAE ainda é incipiente no Brasil. Dos estudos selecionados, um demonstra resultados favoráveis da sua ação germicida frente a diversas cepas clínicas e ATCC (American Type Culture Collection), incluindo bactérias e fungos, em ambiente e materiais de laboratório. Entretanto, não foram testadas micobactérias e não avaliou DAN em endoscópios ${ }^{(25)}$. Outra publicação que analisou a ação de diferentes desinfetantes frente a biofilme em lumens, simulando os canais de endoscópio, teve os piores resultados nos ensaios com $A A E^{(17)}$.

Estudos descritivos ainda apontam para uso frequente do GLU, mas já têm sido adotados germicidas alternativos em parcela significativa dos serviços ${ }^{(26-27)}$. O uso de processadoras automáticas, com diferentes germicidas, é abordado em várias publicações, demonstrando tendência ao abandono do processamento manual $^{(18,26-30)}$. Entretanto, mesmo utilizando desinfetantes adequados, processadoras sem manutenção ou com falhas no desempenho e equipe mal treinada podem causar contaminação do endoscópio, casos de infecção e outros eventos adversos ${ }^{(29-33)}$.

Quanto à toxicidade, os estudos reforçam os cuidados necessários para minimizar os riscos ocupacionais no manuseio dos desinfetantes ${ }^{(31,34)}$. Dois estudos abordam eventos adversos em pacientes submetidos a procedimentos com material desinfetado pelo GLU: seis casos de retocolite pós-colonoscopia, relacionados à falha no sistema de enxágue da reprocessadora ${ }^{(29)}$, e dois casos graves de lesão em orofaringe após ecocardiograma transesofágico, por sonda impregnada com resíduos de GLU ${ }^{(35)}$.

A literatura contra indica o uso de OPA em cistoscópios, devido aos casos de anafilaxia em pacientes oncológicos submetidos a repetidas cistoscopias ${ }^{(31,36-39)}$. Um dos estudos afirma não ter evidenciado qualquer sinal de toxicidade entre os profissionais, mas ressalta que o processamento foi mecanizado, o que minimiza os riscos ocupacionais $^{(28)}$.

Dois estudos relatam casos de colite relacionados ao uso de AP na DAN dos colonoscópios; um devido à falha no enxágue manual $^{(33)}$ e outro por erro na programação da reprocessadora ${ }^{(30)}$. Os estudos não relataram casos de toxicidade ocupacional. Apenas 
uma publicação abordou eventos adversos relacionados à $\mathrm{AAE}$ : dois casos de colite, em serviço de endoscopia de um hospital universitário brasileiro ${ }^{(40)}$.

Quatro estudos abordaram danos nos endoscópios, potencialmente relacionados aos germicidas $^{(27,34,41-42)}$. O guideline da Sociedade Americana de Endoscopia Gastrointestinal afirma que a durabilidade destes equipamentos ainda é pouco conhecida, com carência de dados publicados sobre problemas na funcionalidade ou prejuízos ao processo de desinfecção, após certo número de anos ou de procedimentos ${ }^{(34)}$. Um relato interessante aborda a identificação de Pseudomonas aeruginosa, de mesmo padrão de antibiograma, em secreção traqueal de vários pacientes críticos submetidos à broncoscopia. A investigação do surto concluiu que estava relacionado ao uso de um broncoscópio específico que apresentava danos nos canais internos e na estrutura ${ }^{(42)}$, levando à permanência de sujidade, formação de biofilme e prejuízo da ação germicida.

A literatura destaca a alta compatibilidade do GLU, mas alerta sobre sua ação na fixação de material orgânico, o que pode levar à obstrução dos canais, caso não seja realizada limpeza eficiente $^{(17)}$. Em estudo descritivo das práticas de DAN, em região da Itália, $67 \%$ dos serviços ainda utilizava GLU e 77\% afirmavam acreditar que a solução desinfetante poderia danificar os endoscópios $^{(27)}$. Um estudo descritivo para avaliar o tempo de uso de fibroscópios, submetidos à desinfecção automatizada por OPA, monitorou a ocorrência de danos nos equipamentos e concluiu que, quanto mais delgada a fibra, maior a chance de dano e que o manuseio por equipe treinada é fundamental para conservação do equipamento. $\mathrm{Na}$ amostra não houve dano relacionado diretamente à solução desinfetante ${ }^{(41)}$.

Não foram identificados estudos avaliando danos relacionados ao AP ou AAE.

\section{CONCLUSÕES}

A principal limitação da presente revisão é a carência de estudos de alto nível de evidência sobre os desinfetantes de alto nível, frente aos desfechos analisados, demonstrando a necessidade de desenvolvimento de novas pesquisas com elevado rigor metodológico para compreensão adequada dos fenômenos. Com base nos estudos analisados e nas evidências disponíveis verifica-se a efetividade das soluções de AP e OPA na inativação de microrganismos vegetativos, sejam bactérias, fungos, vírus e micobactérias, desde que obedecidas as condições de uso estabelecidas pelo fabricante, adesão às boas práticas de DAN e adequado funcionamento das processadoras automáticas de endoscópios. Foi evidenciada a tolerância intrínseca de micobactérias de crescimento rápido ao GLU. Há necessidade de mais estudos sobre a eficácia da $\mathrm{AAE}$, principalmente quanto à sua ação microbicida e, especialmente, a inativação de $M$. massilie. Microrganismos da subclasse Coccidia permanecem um desafio, pois não são inativados por nenhum método químico de DAN disponível no Brasil.

Quanto à toxicidade ocupacional é imperativo o uso de medidas de proteção individual e do ambiente no manuseio de qualquer produto químico, mesmo que não haja relatos concretos de eventos adversos relacionados ao uso de AP e AAE. Dos desinfetantes estudados, o GLU foi o mais citado quanto à toxicidade, reforçando a necessidade de medidas adicionais de controle da saúde ocupacional, caso não seja possível sua substituição por germicidas menos tóxicos. Todas as etapas do processamento devem ser rigorosamente seguidas para garantir a segurança do paciente, em especial a remoção efetiva de resíduos químicos por enxágue abundante. Permanece a contraindicação do uso de OPA para DAN de cistoscópios pelo risco de reações anafiláticas.

Não foi identificado estudo que relacione danos aos endoscópios pelas soluções de AP, OPA e AAE, apesar de ser uma preocupação frequente, tanto dos fabricantes de endoscópios, quanto dos serviços de saúde. Não há evidências suficientes para afirmar a inferioridade de algum germicida quanto a danos no equipamento, ressaltando que, quando se trata de $\mathrm{AP}$, diferentes formulações estão disponíveis no mercado, algumas explicitamente indicadas para DAN de endoscópios pelos fabricantes e outras formulações sem esta indicação clara. Estudos destacam a importância de que todos os profissionais que manipulam o equipamento sejam devidamente treinados para garantir a 
preservação da vida útil destes equipamentos.

O conhecimento sobre os germicidas possibilita sua adequada seleção para o processamento de cada tipo de endoscópio, considerando-se características químicas, espectro de ação e restrições na opção do desinfetante, assim como a capacitação da equipe executora para as boas práticas do processamento visando prevenir eventos adversos relacionados aos procedimentos endoscópios, toxicidade ocupacional e danos nos equipamentos.

\section{DECLARAÇÃO DE CONFLITOS DE INTERESSE E AGRADECIMENTOS}

Os autores declaram não possuírem conflito de interesses com a indústria de produtos para a saúde ou de germicidas. Estudo realizado com apoio financeiro da Organização Panamericana de Saúde ao Núcleo de Avaliação de Tecnologia em Saúde do Hospital de Clínicas da Universidade Estadual de Campinas.

Agradecimento especial à Prof ${ }^{\mathrm{a}}$. Dr ${ }^{\mathrm{a}}$. Kazuko Uchikawa Graziano (Escola de Enfermagem da Universidade de São Paulo) pela revisão técnica.

\section{REFERÊNCIAS}

1. Beilenhoff $U$, Neumann CS, Rey JF, Biering H, Blum $R$, Cimbro M, et al. ESGE-ESGENA guideline: cleaning and disinfection in gastrointestinal endoscopy. Endoscopy. 2008;40:939-57.

2. Rutala WA, Weber DJ, Weinstein RA, Siegel JD, Pearson ML, Chinn RYW, et al. Guideline for disinfection and sterilization in healthcare facilities, 2008. Atlanta (EUA): Centers for Disease Control and Prevention; 2008.

3. ECRI Institute. Top 10 health technology hazards for 2013. [Internet] [acesso em 10 jan 2013]. Disponível: https://www.ecri.org/Pages/default.aspx

4. Brasil. Agência Nacional de Vigilância Sanitária (ANVISA). Resolução da Diretoria Colegiada n.15 de 15 de março de 2012. Dispõe sobre requisitos de boas práticas para o processamento de produtos para saúde e dá outras providências. ANVISA; 2012.

5. Brasil. Agência Nacional de Vigilância Sanitária (ANVISA). Resolução da Diretoria Colegiada n. 6, de $1^{\circ}$ de março de 2013. Dispõe sobre os requisitos de Boas Práticas de Funcionamento para os serviços de endoscopia com via de acesso ao organismo por orifícios exclusivamente naturais. Diário Oficial da União - Seção 1 - No 42, 4 de março de 2013. ANVISA; 2013.

6. Brasil. Agência Nacional de Vigilância Sanitária (ANVISA). Resolução da Diretoria Colegiada n. 35, de 16 de agosto de 2010. Dispõe sobre o Regulamento Técnico para produtos com ação antimicrobiana utilizados em artigos críticos e semicríticos. ANVISA; 2010.

7. Brasil. Agência Nacional de Vigilância Sanitária (ANVISA). Informe Técnico n. 4 de março de 2007. Glutaraldeído em estabelecimentos de assistência à saúde: Fundamentos para a utilização. ANVISA; 2007.

8. São Paulo. Secretaria de Estado de Saúde. Resolução SS - 27, de 28 de fevereiro de 2007. Aprova norma técnica que institui medidas de controle sobre o uso do Glutaraldeído nos Estabelecimentos Assistenciais de Saúde. São Paulo, 2007.

9. Brasil. Agência Nacional de Vigilância Sanitária (ANVISA). Nota Técnica em 08 de agosto de 2008: Micobactérias. [Internet] [acesso em 07 jan 2013]. Disponível:

10. Lorena NS de O, Duarte RS, Pitombo MB. Infecção por micobactérias de crescimento rápido após procedimentos videocirúrgicos: a hipótese do glutaraldeído. Rev. Col. Bras. Cir. 2009;36(3):266-7.

11. Lorena NSO, Pitombo MB, Côrtes PB, Maya MCA, Silva MG, Carvalho ACS, et al. Mycobacterium massiliense clone BRA100 associado a infecções pós-cirúrgicas: resistência a altas concentrações de glutaraldeído e produtos alternativos para desinfecção de alto nível. Acta cir. bras. 2010;25(5):455-9.

12. Brasil. Agência Nacional de Vigilância Sanitária (ANVISA). Resolução da Diretoria Colegiada n. 8, de 27 de fevereiro de 2009. Dispõe sobre as medidas para redução da ocorrência de infecções por Micobactérias de Crescimento Rápido - MCR em serviços de saúde. ANVISA; 2009.

13. Brasil. Agência Nacional de Vigilância Sanitária (ANVISA). Resolução RDC n. 31, de 4 de julho de 2011. Dispõe sobre a indicação de uso dos produtos saneantes na categoria "Esterilizante", para aplicação sob a forma de imersão, a indicação de uso de produtos saneantes atualmente categorizados como "Desinfetante Hospitalar para Artigos Semicríticos" e dá outras providências. ANVISA, 2011.

14. Kaigen Co. Ltd. Catálogo do equipamento Clean Top WM-S, versão para mercado brasileiro. [Internet] [acesso em 25 ago 2012]. Disponível: http://www. omed-catalogue.com/UserFiles/File/Kaigen.pdf

15. Ministério da Saúde (BR). Secretaria de Ciência, Tecnologia e Insumos Estratégicos. Diretrizes 
metodológicas: elaboração de pareceres técnicocientíficos. $3^{a}$ ed. Brasília (DF): Ministério da Saúde; 2011.

16. Canadian Agency for Drugs and Technologies in Health - CADTH. Sterilization Equipment and Requirements for Endoscopy Equipment: A Review of the Clinical Evidence and Guidelines. Canadá, 2012.

17. Pineau L, Desbiquois C, Marchetti B, Duc DL. Comparison of the fixative properties of five disinfectant solutions. J. Hosp. Infect. 2008;68:171-7.

18. Balsamo AC, Graziano KU, Schneider RP, Antunes Júnior M, Lacerda RA. Remoção de biofilme em canais de endoscópios: avaliação de métodos de desinfecção atualmente utilizados. Rev Esc Enferm USP. 2012;46(n. esp):91-8.

19. Kovaleva J, Degener JE, Van Der Mei HC. Mimicking disinfection and drying of biofilms in contaminated endoscopes. J. Hosp. Infect. 2010;76:345-50.

20. Souza RQ, Torres LM, Graziano KU, Turrini RNT. Microrganismos da subclasse Coccidia: resistência e implicações para o processamento de materiais de assistência à saúde. Rev Esc Enferm USP. 2012;46(2):466-71.

21. Lorena NSO, Duarte RS, Pitombo MB. Infecção por micobactérias de crescimento rápido após procedimentos videocirúrgicos: a hipótese do glutaraldeído. Rev. Col. Bras. Cir. 2009;36(3):266-7.

22. Duarte RS, Lourenço MC, Fonseca LS, Leão SC, Amorim EIL, Rocha IL, et al. Epidemic of postsurgical infections caused by Mycobacterium massiliense. J. clin. microbiol. 2009;47(7):2149-55.

23. Lorena NSO, Pitombo MB, Bettini M, Côrtes PB, Maya MCA, Silva MG, et al. Mycobacterium massiliense clone BRA100 associado a infecções pós-cirúrgicas: resistência a altas concentrações de glutaraldeído e produtos alternativos para desinfecção de alto nível. Acta cir. bras. 2010;25(5):455-9.

24. Ministério da Saúde (BR). Portaria n. 3.012 de $1^{\circ}$ de dezembro de 2009. Torna pública a proposta de Projeto de Resolução “Regulamento Técnico Mercosul para Produtos com Ação Antimicrobiana Utilizados em Artigos Críticos e Semicríticos, Áreas Críticas e Semi-Críticas e Esterilizantes". Diário Oficial da União. n. 230 - 02/12/09 - p.70. Imprensa Nacional, Brasília (DF): Ministério da Saúde, 2009.

25. Aggarwal R, Chaudhary U, Goel N, Kumar V, Ranjan KP. Evaluation of microbiocidal activity of superoxidized water on hospital isolates. Indian j. pathol. microbiol. 2010;53(4):757.

26. Soares JB, Gonçalves R, Banhudo A, Pedrosa J. Reprocessing practice in digestive endoscopy units of district hospitals: Results of a Portuguese National Survey. European J. Gastroenterol. Hepatology. 2011;23(11):1064-8.

27. Spinzi G, Fasoli R, Centenaro R, Minoli G. Reprocessing in digestive endoscopy units in Lombardy: results of a regional survey. Dig Liver Dis. 2008;40(11):890-6.

28. Kim SY, Lee HS, Hyun JJ, Seo MH, Yim SY, Oh HY, et al. Comparison on the Efficacy of Disinfectants used in automated endoscope reprocessors: PHMBDBAC versus orthophthalaldehyde. Clin. Endosc. 2011;44(2):109-15.

29. Hsu CW, Lin CH, Wang JH, Wang HT, Ou WC, King TM. Acute rectocolitis following endoscopy in health check-up patients--glutaraldehyde colitis or ischemic colitis? Int J Colorectal Dis. 2009;24(10):1193-200.

30. Kara M, Turan I, Polat Z, Dogru T, Bagci S. Chemical colitis caused by peracetic acid or hydrogen peroxide: a challenging dilemma. Endoscopy. 2010;42(Suppl 2):3-4.

31. Clemens JQ, Dowling R, Foley F, Goldman HB, Gonzalez CM, Tessier C, et al. Joint AUA/SUNA white paper on reprocessing of flexible cystoscopes. J. urol. 2010;184(6):2241-5.

32. Chroneou A, Zimmerman SK, Cook S, Willey S, EyreKelly J, Zias N, et al. Molecular typing of mycobacterium chelonae isolates from a pseudo-outbreak involving an automated bronchoscope washer. Infect. control hosp. epidemiol. 2008;29(11):1088-90.

33. Coriat R, Chaput U, Ismaili Z, Chaussade S. What induces colitis? Hydrogen peroxide or peracetic acid. Endoscopy. 2008;40(3):231.

34. Petersen BT, Chennat J, Cohen J, Cotton PB, Greenwald DA, Kowalski TE, et al. Multisociety guideline on reprocessing flexible gastrointestinal endoscopes: 2011. Gastrointest. endosc. 2011;73(6):1075-84.

35. Irie T, Miura N, Sato I, Okamura M, Echigo N, Goto T. The occurrence of injury and black denaturalization of the lips, tongue, and pharynx because of phtharal use for disinfection of transesophageal echocardiographic equipment and establishment of a safe disinfection method. J. cardiothorac. vasc. anesth. 2012;26(2):1819.

36. Cooper DE, White AA, Werkema AN, Auge BK. Anaphylaxis following cystoscopy with equipment sterilized with Cidex OPA (ortho-phthalaldehyde): a review of two cases. J Endourol. 2008;22(9):2181-4

37. Suzukawa M, Komiya A, Koketsu R, Kawakami A, Kimura $M$, Nito T, et al. Three cases of ortho-phthalaldehydeinduced anaphylaxis after laryngoscopy: detection of specific IgE in serum. Allergol Int. 2007;56(3):313-6. 
38. Hasegawa G, Morinaga T, Ishihara Y. Orthophthalaldehyde enhances allergen-specific IgE production without allergen-specific lgG in ovalbuminsensitized mice. Toxicol. Lett. 2009;185(1):45-50.

39. Cooper DE, White AA, Werkema AN, Auge BK. Anaphylaxis following cystoscopy with equipment sterilized with cidex OPA (ortho-phthalaldehyde): a review of two cases. J. endourol. 2008;22(9):2181-4.

40. Souza JLS, Ribeiro TM, Borges LV, Silva JGN. Electrolyzed acid water can cause colitis? Endoscopy. 2008;40(7): 620

41. Statham MM, Willging JP. Automated high-level disinfection of nonchanneled flexible endoscopes: Duty cycles and endoscope repair. Laryngoscope. 2010;120(10):1946-9.

42. Granados DCA, Jones MY, Thiphasone KT et al. Outbreak of pseudomonas aeruginosa infection associated with contamination of a flexible bronchoscope. Infect Control Hosp Epidemiol. 2009;30(6):550-5. 